\title{
An Innovative Ultrasonic Apparatus and Technology for Diagnosis of Freeze-Drying Process
}

\author{
Chin-Chi Cheng ${ }^{1, * \mathbb{D}}$, Yen-Hsiang Tseng ${ }^{2}$ and Shih-Chang Huang ${ }^{1}$ \\ 1 Department of Energy and Refrigerating Air-Conditioning Engineering, \\ National Taipei University of Technology, Taipei 10608, Taiwan; albertschuang@gmail.com \\ 2 Tai Yiaeh Enterprise Co., Ltd., New Taipei City 23942, Taiwan; yhtntut@gmail.com \\ * Correspondence: newmanch@ntut.edu.tw; Tel.: +886-2-27712171 (ext. 3527)
}

Received: 17 April 2019; Accepted: 8 May 2019; Published: 11 May 2019

\begin{abstract}
The freeze-drying process removes water from a product through freezing, sublimation and desorption procedures. However, the extreme conditions of the freeze-drying environment, such as the limited space, vacuum and freezing temperatures of as much as $-50{ }^{\circ} \mathrm{C}$, may block the ability to use certain diagnostic sensors. In this paper, an ultrasonic transducer (UT) is integrated onto the bottom of a specially designed frozen bottle for the purpose of observing the freeze-drying process of water at varying amounts. The temperatures and visual observations made with a camera are then compared with the corresponding ultrasonic signatures. Among all of the diagnostic tools and technologies available, only ultrasonic and visual records are able to analyze the entire progression of the freeze-drying process of water. Compared with typical experiment settings, the indication of drying point for water by the amplitude variations of ultrasonic $\mathrm{L}^{3}$ echo could reduce the process period and energy consumption. This study demonstrates how an innovative frozen bottle, an integrated ultrasonic sensor and diagnostic methods used to measure and optimize the freeze-drying process of water can save energy.
\end{abstract}

Keywords: freeze-drying process diagnosis; ultrasonic transducer (UT); freezing/drying point; drying period

\section{Introduction}

Dehydration extends food's usage period longer than that of fresh food by preserving it in a stable and safe condition [1,2]. The conventional methods of drying include solar drying, air drying, spray drying [3], microwave drying [4], infrared drying, fluidized bed drying [5], spouted bed drying, vacuum drying and freeze-drying [6]. Drying methods can be separated into natural and artificial categories. Artificial methods are more advantageous than the natural methods [7] because they can remove large amounts of moisture efficiently by being able to control the different parameters involved such as the temperature, drying air flux and time of drying and so forth. [8]. For long-term storage of food, drug and biopharmaceutical products, most manufacturers utilize the freeze drying process, due to its advantages including better stability, easy handling and storage, as well as better overall product quality $[9,10]$.

The freeze-drying process is comprised of the freezing, primary drying and then secondary drying stages [11] to remove the water from a product. The water contained in food is cooled down and becomes ice during the freezing stage. This stage governs the sublimation and desorption rates and the quality of the lyophilized product [12]. Then, in the primary drying stage, the air in the vacuum chamber is exhausted and the chamber pressure is reduced below the vapor pressure of ice. Meanwhile, the shelf temperature increases gradually to sublimate the ice. The residual water inside the food will be desorbed thoroughly in the secondary drying stage [13]. 
In the freezing stage, the accuracy of the freezing point data is related to the water activity, frozen water [14], freezing and the thawing of frozen food. The freezing point is also important in order to estimate the freezing time, the end point of freezing and the fraction of unfrozen water in food. Then, in the primary drying stage, the chamber pressure and food temperature [15] decides the sublimation rate of the ice, primary drying period, dried pore structure and product quality. A lower product temperature and the corresponding lower vapor pressure of the ice can result in longer primary drying times and higher manufacturing costs [16]. However, if the product temperature increases above the "critical formulation temperature," this may lead to losing the pore structure, to shrinkage or to fully collapsing. In the secondary drying stage, the product temperature controls the rate of desorption and the obtainable moisture level. Further reduction of the chamber pressure is not necessary in this stage [17]. Secondary drying times are usually designed to achieve a reduction of moisture content within the dried product to less than 1\% [18]. Due to the importance of these parameters and its wider applications to the freeze drying process, the estimated freezing/drying points and the ability to model these properties is crucial in food processing (freezing and drying) and food stability during storage $[10,19]$.

Being able to perform real-time process diagnosis will be beneficial to understanding the complex interplay between the different elements during the freeze-drying process to better enhance quality control procedures. However, the extreme conditions of the freeze-drying environment, such as the limited space, vacuum and freezing temperatures as low as $-50{ }^{\circ} \mathrm{C}$, may block the ability to use certain diagnostic sensors $[6,20]$. The typically used diagnostic tools for real-time measurement of the freeze-drying process are temperature and pressure sensors [20,21]. In order to provide temperature information, a temperature sensor is put in direct contact with a frozen sample [21]. However, inconveniences arise because it is often not easy to remove the sensor after the freeze-drying process. Additionally, using this diagnostic method on drug and biopharmaceutical products may cause undesired contamination due to a sensor being in direct contact with the sample. The chamber pressure is measured by the pressure sensor or vacuum gauge. The measured chamber pressure value cannot directly indicate the physical variation of frozen product real-time during the freeze-drying process $[20,22]$. In this paper, an idea for diagnosing the physical property variations of a product in the frozen bottle to provide additional information for a machine system is presented, as shown in Figure 1.

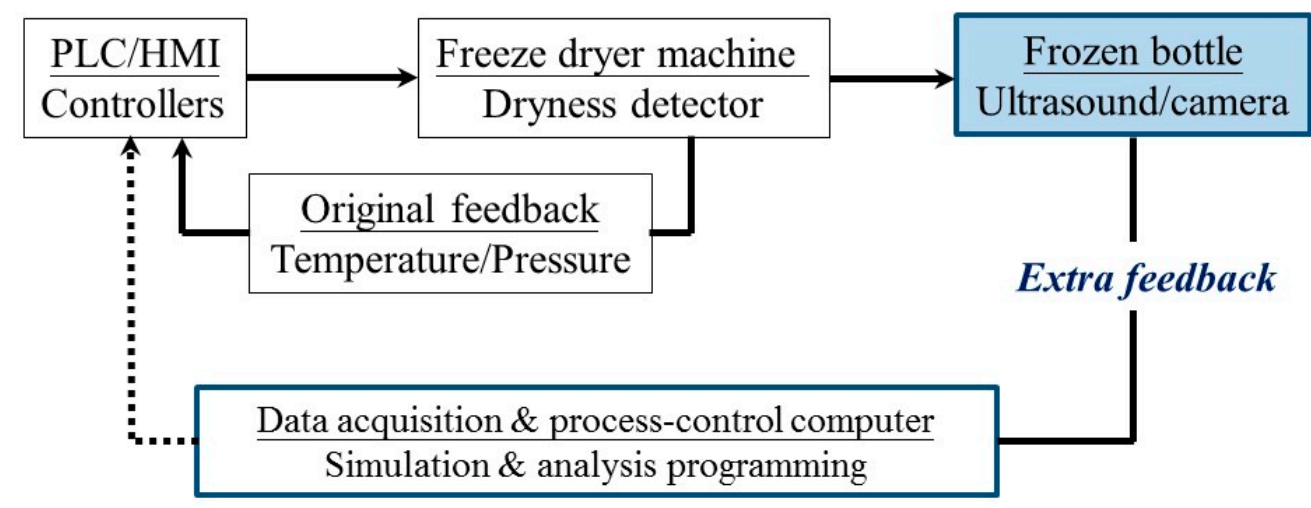

Figure 1. Controlling structure of the freeze-drying process by using the innovative frozen bottle method.

In order to circumvent the limitations of the mentioned sensors and provide real-time process diagnosis, the ultrasonic technique is one of the most widely known non-destructive and non-intrusive methods [23]. The fundamental properties of ultrasonic signals include reflection and transmission coefficients, velocity, attenuation and scatter signals given off from the materials. These signatures have specific relationships with properties of materials [24], process variations [25] and sample quality [26]. Ultrasonic echoes can also detect the temperature [27,28] and pressure [29] of a material. Passot et al. utilized ultrasonic technology to decrease the sublimation time during the primary drying stage by 
controlling the nucleation temperature [30]. The authors presented an innovatively designed frozen bottle with an ultrasonic transducer and ultrasonic technology to be utilized for the diagnosis of the freezing point during the frozen process in our previous paper [22]. In this study, the ultrasonic technique will be applied for real-time diagnosis of the freeze-drying process. An ultrasonic transducer (UT) is integrated into the bottom of a frozen bottle. During the freeze-drying process at various amounts of water, the process is analyzed by using ultrasonic technology to evaluate the freezing/drying points and the drying period to optimize the process and save energy.

\section{Design of Frozen Bottle with Ultrasonic Transducer}

In order to solve the aforementioned limitations regarding the transmission of signals in a vacuum, as well as the limitations of being unable to view the process using the steel freezing bottle apparatus or the opaque samples, an innovative freezing bottle apparatus was designed as shown in Figure 2 . The innovatively designed container used for freezing is comprised of two parts: a steel plate as the bottom holder and a transparent polymethylmethacrylate (PMMA) tube as the side wall of the container. Figure 2a shows the side view of the frozen bottle. A steel plate with a diameter of $25 \mathrm{~mm}$ and a height of $6 \mathrm{~mm}$ was designed for better heat transmission with the heating/cooling shelf. A transparent PMMA tube measuring $31 \mathrm{~mm}$ high, with a diameter of $21 \mathrm{~mm}$ and a thickness of $2 \mathrm{~mm}$ was designed for better visibility. The steel plate and PMMA tube were then glued together. Figure $2 b$ shows the top view of the apparatus. Figure $2 \mathrm{c}$ shows the bottom view of the apparatus. The UT is comprised of $\mathrm{Pb}\left(\mathrm{Zr}_{\mathrm{x}} \mathrm{Ti}_{1-\mathrm{x}}\right) \mathrm{O}_{3}$ (PZT) material and integrated into the cavity of steel plate using the sol-gel spray technique, as described in previous publications $[22,24,31]$. The operational temperature range of the UT is between -100 and $400{ }^{\circ} \mathrm{C}$.

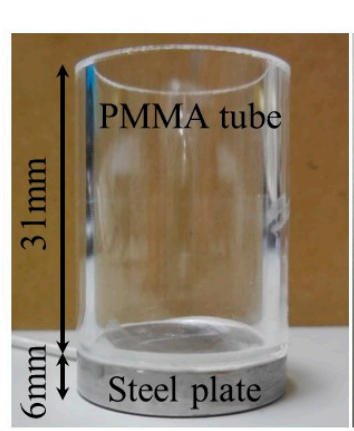

(a)

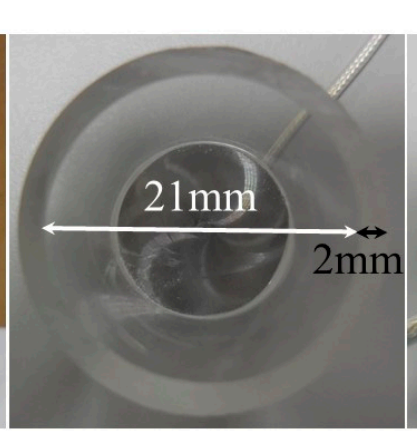

(b)

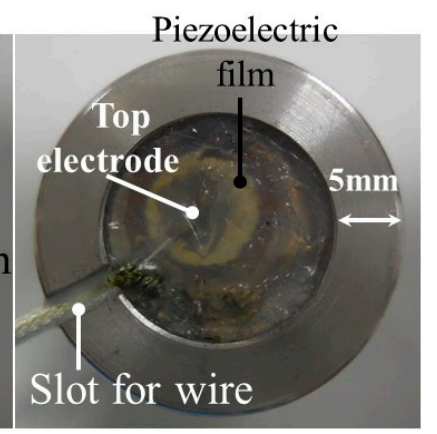

(c)

Figure 2. Photographs of the designed apparatus from (a) the side, (b) the top and (c) the bottom view.

To understand the transmission paths of the ultrasonic signals within the apparatus, a schematic view of the apparatus placed upright is displayed in Figure 3. A temperature sensor (Type T thermocouple) was installed in the middle of the apparatus for measuring the water/ice temperature. The temperature can be recorded and then compared with the ultrasonic signals received during the freeze-drying process. As shown in Figure 3a, an ultrasonic transducer (UT) was integrated onto the bottom of the steel plate. When electric pulses are applied to the piezoelectric film, the ultrasonic signals are transmitted into the steel plate. $\mathrm{L}^{\mathrm{n}}(\mathrm{n}=1,2, \ldots)$ denotes the nth round trip of longitudinal ultrasonic echoes reflected from the interface of the steel plate/water or ice and $\mathrm{L}_{\mathrm{w}}$ is the echo reflected from the water/air interface. The $\mathrm{L}^{3}$ and $\mathrm{L}_{\mathrm{w}}$ echoes are used to monitor the freeze-drying process and water/ice state. The height of the water level and the thickness of the bottom of the apparatus are denoted as $\mathrm{H}$ and $\mathrm{D}$, respectively. 

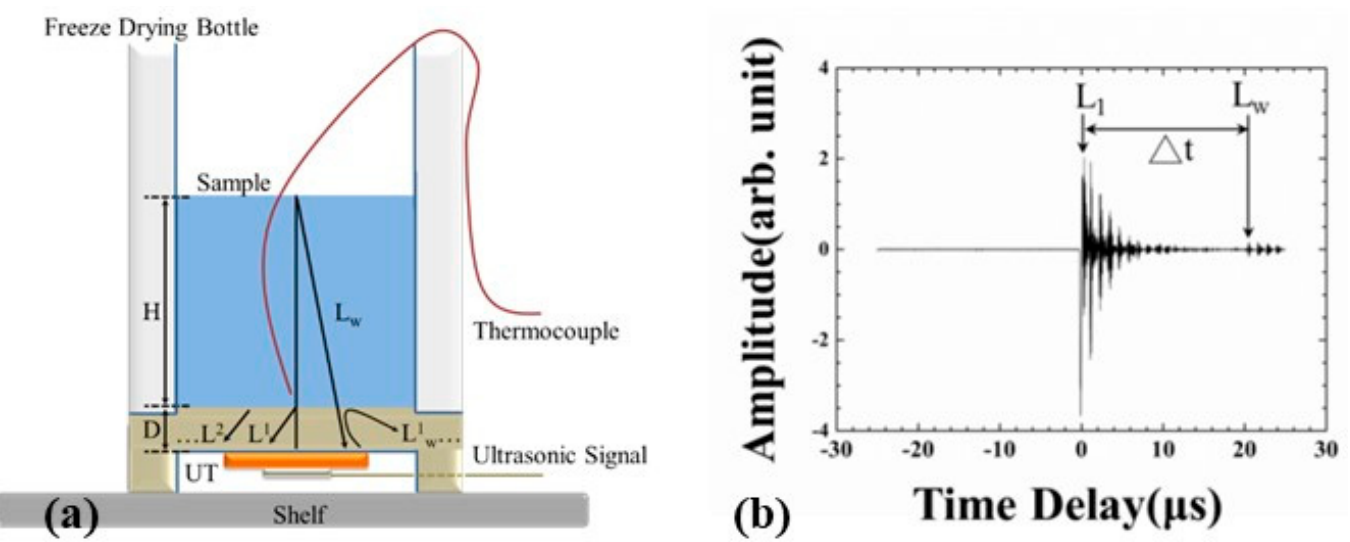

Figure 3. (a) Schematic drawing of cross-section of the designed apparatus with an ultrasonic transducer (UT) and thermocouple and (b) shows the typical ultrasonic echoes acquired by the UT.

When the water was fed into the apparatus, the typical ultrasonic signals acquired by the UT are presented in Figure 3b. It was observed that the $\mathrm{L}^{1}$ echo, which reflected from the steel plate/water or ice interface, appeared as $0.81 \mu$ s and remained so during the entire process. The operating frequency of the ultrasonic transducer was $9.13 \mathrm{MHz}$ and the $-6 \mathrm{~dB}$ bandwidth was $8.0 \mathrm{MHz}$. The signal to noise ratio (SNR) for the ultrasonic $\mathrm{L}^{1}$ echo was $38.5 \mathrm{~dB}$. The $\mathrm{L}_{\mathrm{w}}$ echo, which propagated in the water and reflected from the water/air interface, was observed at $20.39 \mu \mathrm{s}$. Following the $\mathrm{L}^{1}$ and $\mathrm{L}_{\mathrm{w}}$ echoes, there were several echoes reflected from the steel plate/water or ice interface. The desired ultrasonic echoes were detected by the acquiring windows of the acquiring system. The time delay difference between the $\mathrm{L}^{1}$ and $\mathrm{L}_{\mathrm{w}}$ echoes is denoted as $\Delta \mathrm{t}$.

\section{Experiments}

In order to confirm the hypothesis that the apparatus was able to perform improved diagnostics of the freeze-drying process in a vacuum, a $4 \mathrm{~L}$ air-cooled split-type shelf freeze-drying machine, equipped with vacuum chamber, shelf, control units, refrigeration system and vacuum pump, was used to carry out all experiments, as shown in Figure 4a. The vacuum chamber was used for freezing and drying the samples under temperature conditions ranging from +50 to $-40{ }^{\circ} \mathrm{C}$ and pressures from 760 to 0.05 Torr. The apparatus was set on the shelf of vacuum chamber for the freeze-drying process. The control unit was composed of a programmable logic controller (PLC) and a human-machine interface (HMI) for controlling the freeze-drying process. The measured temperature data from the thermocouple were recorded by the PLC control unit every second during the freeze-drying process.

The ultrasonic signal is triggered and received by the pulse/receive unit (5072PR, Olympus, Japanese), as shown in Figure 4b. It is equipped with a broadband negative spike pulser and receiver, which can be operated in reflection or transmission mode. All the experiments in this study were carried out using the ultrasonic pulse/receiver unit's pulse-echo mode. The ultrasonic signals were acquired every second during the entire cycle. The ultrasonic signals received during the freeze-drying process were monitored and recorded with the digital storage USB oscilloscope (DSO-U2400, Perytech, Taipei, Taiwan), as shown in Figure 4c.

To compare the temperatures and ultrasonic signals, a charge-coupled device (CCD) camera, digital video recorder (DVR) and PC were used to capture dynamic images of the apparatus during the freeze-drying process, as shown in Figure 4d-e. The CCD camera (CV-M10BX, JAI, Japan) is a progressive scan camera with a standard interlaced video output at a resolution compatible with VGA or SVGA formats. The camera was equipped with a $35 \mathrm{~mm}$ lens for better resolution. The DVR (08KD, Kingnet, New Taipei City, Taiwan) is an 8-channel recorder that uses the H.264 image compression format. 

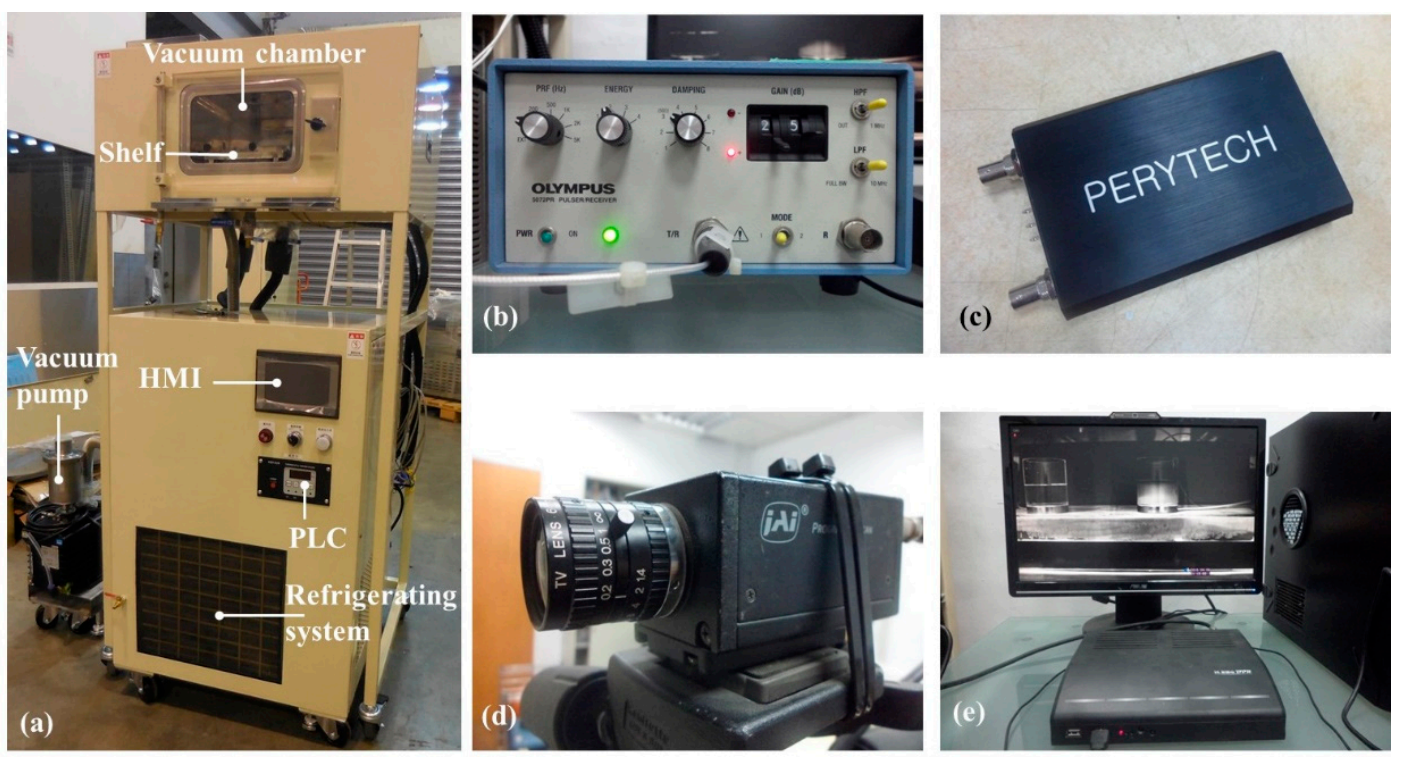

Figure 4. Photographs of (a) the split-type freeze-drying machine with vacuum chamber, controller unit, refrigeration unit and vacuum pump, (b) the ultrasonic pulse/receive unit, (c) a PC-based digital oscilloscope, (d) Charge-coupled device (CCD) camera, (e) digital video recorder (DVR) and PC.

In this study, different amounts of water at levels of 5, 10 and $15 \mathrm{~mm}$ were put into the apparatus for the duration of the freeze-drying process. The settings of a typical freeze-drying procedure are outlined in Table 1 . The shelf temperature was set at $-30{ }^{\circ} \mathrm{C}$ to freeze the water and the freezing period was $120 \mathrm{~min}$. During the freezing period, the water in the apparatus/container was cooled down and it began to freeze. After enough cooling and freezing, the chamber was exhausted and the chamber pressure was reduced from 760 to 0.17 Torr within several seconds. Then the primary and secondary drying processes were started and the ice sublimated into gas continuously. The shelf temperature was incrementally increased by 10 degree intervals from -30 to $10^{\circ} \mathrm{C}$ at heating and pausing periods of 60 and $120 \mathrm{~min}$, respectively. The pausing period of $0{ }^{\circ} \mathrm{C}$ is $300 \mathrm{~min}$ to sublimate ice further. During the sublimation of the ice, the chamber pressure was reduced further to 0.036 Torr.

Table 1. The typical procedure used for the freeze-drying process.

\begin{tabular}{cccccc}
\hline $\begin{array}{c}\text { Freezing } \\
\text { Temp. }\left({ }^{\circ} \mathbf{C}\right)\end{array}$ & $\begin{array}{c}\text { Freezing } \\
\text { Period (min) }\end{array}$ & $\begin{array}{c}\text { Chamber } \\
\text { Pressure (Torr) }\end{array}$ & $\begin{array}{c}\text { Drying } \\
\text { Temp. }\left({ }^{\circ} \mathbf{C}\right)\end{array}$ & $\begin{array}{c}\text { Heating } \\
\text { Period (min) }\end{array}$ & $\begin{array}{c}\text { Pausing } \\
\text { Period (min) }\end{array}$ \\
\hline \multirow{3}{*}{30} & \multirow{2}{*}{120} & 760 & -20 & 60 & 120 \\
& & 1 & -10 & 60 & 120 \\
& 0.17 & 0 & 60 & 300 \\
\end{tabular}

\section{Results and Discussions}

For exploring the physical phenomena that occur during the freeze-drying process and searching for the indicators of freezing or drying completeness, the measured temperature and pressure in the vacuum chamber, ultrasonic echoes and velocity of the water/ice and visual observation during the freeze-drying process are analyzed in the following sections.

\subsection{Temperature and Pressure Variations in the Vacuum Chamber during the Freeze-Drying Process}

Temperature and pressure variations during the freeze-drying process have a close relationship with the state of the water/ice and both affect the size of the ice crystal nuclei and the freeze-dried product's quality. In the experiment, the measured room, shelf, cold trap, water/ice temperatures and pressures for the freezing and drying periods of the freeze-drying procedure of the water at a level of 
$15 \mathrm{~mm}$ are shown in Figure 5a,b, respectively. In Figure $5 \mathrm{a}$, the room temperature was $32{ }^{\circ} \mathrm{C}$ during the entire process and the chamber pressure was kept at 760 Torr for the experiment's duration of $120 \mathrm{~min}$. The shelf and cold trap temperatures were set at -30 and $-40{ }^{\circ} \mathrm{C}$ and reached the desired values at 40 and $15 \mathrm{~min}$, respectively. The water temperature was $32.1^{\circ} \mathrm{C}$ in the beginning and was cooled down to a supercooled state of $-0.4^{\circ} \mathrm{C}, 16.1 \mathrm{~min}$ into the experiment. After the latent heat of the water was released completely, the phase change from water to ice was completed at $43.7 \mathrm{~min}$ and the ice temperature was $-16.5^{\circ} \mathrm{C}$. Therefore, the cooling $\left(\Delta \mathrm{P}_{\mathrm{CT}}\right)$ and freezing $\left(\Delta \mathrm{P}_{\mathrm{FT}}\right)$ period determined by the sample temperature could be defined as the period from the start of cooling to the supercooled state and from the supercooled state to the phase change end, respectively.
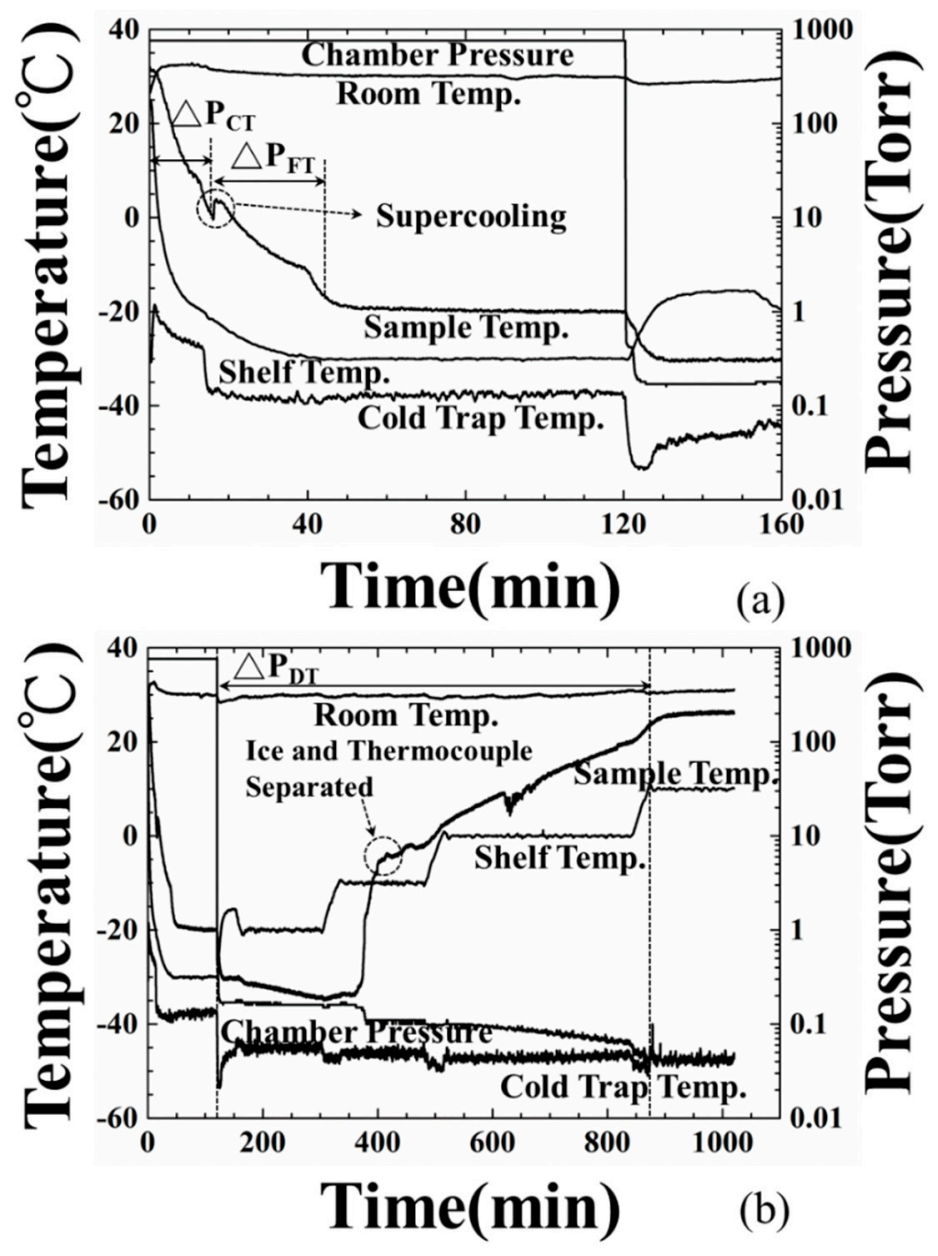

Figure 5. Temperature (room, shelf, sample, cold trap) and pressure (chamber) variations during freeze-drying process at (a) the freezing stage and (b) drying stage.

At the 120-min mark of the experiment, the drying procedure started and the chamber pressure was reduced from 760 to 0.17 Torr. The shelf temperature was increased in $10^{\circ} \mathrm{C}$ increments, from -30 to $10^{\circ} \mathrm{C}$, according to the designed schedule in Table 1 . The cold trap temperature was cooled down further to condense the vapor exhausted from the chamber. The chamber pressure was reduced further to 0.036 Torr during the drying process. At the 370-min mark, the ice temperature increased suddenly from -36 to $-10{ }^{\circ} \mathrm{C}$ due to the sublimation of the ice and gradually increased to $23^{\circ} \mathrm{C}$ by the end of the experiment. This abnormal situation was due to the detachment of the thermocouple from the ice and will be confirmed in the following section. Consequently, the ice temperatures during the second drying period is not available. The drying end could not be estimated from the temperature information and the typical experiment procedure would end at the 1020-min mark of the experiment. 


\subsection{Amplitude Variation of Ultrasonic Signals during the Freeze-Drying Process}

The application of freeze-drying technology can guarantee the product's quality. However, the process diagnosis and control will benefit by guaranteeing product quality and energy conservation. The conventional tools for monitoring this process may be limited to visual observation and temperature measurement. According to the authors' knowledge, utilizing ultrasonic technology to monitor the freeze-drying process is rare. In order to investigate the correlation between the observed ultrasonic signals and the freeze-drying process of water, the amplitudes of the $\mathrm{L}^{3}$ and $\mathrm{L}_{\mathrm{w}}$ echoes in Figure $3 \mathrm{~b}$ with respect to the process time were acquired and presented in Figure 6. The details of freeze-drying process measured by the amplitude variations of ultrasonic $\mathrm{L}^{3}$ and $\mathrm{L}_{\mathrm{w}}$ echoes were demonstrated as follows:

(1) At the 3.0-min mark: Water was poured into the container. At this moment, the amplitude of ultrasonic $\mathrm{L}^{3}$ echo decreased and $\mathrm{L}_{\mathrm{w}}$ echo appeared, due to the fact that a part of the ultrasonic energy transmitted into the water through the steel plate/water interface. Water started to cool down.

(2) At the 19.2-min mark: The amplitudes of the $\mathrm{L}^{3}$ and $\mathrm{L}_{\mathrm{w}}$ echoes decreased further, due to the variation of water acoustic impedance. In this supercooling period, this ultrasonic phenomenon may indicate the appearance of ice crystals. The alteration of water property will cause electrical impedance changing [32]. Hence, the amplitude decreasing point of the $\mathrm{L}^{3}$ and $\mathrm{L}_{\mathrm{w}}$ echoes is defined as the freezing point of water and the cooling period $\left(\Delta \mathrm{P}_{\mathrm{CUT}}\right)$ determined by the amplitude of the $\mathrm{L}^{3}$ echo is defined as the period from water-in to the freezing point.

(3) At the 43.0-min mark: The amplitude of the $\mathrm{L}^{3}$ echo increased to the relative maximum value and that of the $\mathrm{L}_{\mathrm{w}}$ echo increased to a stable level, due to the stable ultrasonic impedance. This ultrasonic phenomenon may indicate phase change end of water and a flat ice surface. Hence, the freezing period $\left(\Delta \mathrm{P}_{\mathrm{FUT}}\right)$ determined by the ultrasonic $\mathrm{L}^{3}$ echo is defined as the period from the freezing point to the phase change end.

(4) At the 125.0-min mark: The chamber was exhausted and the ice started to sublimate at the 120-min mark. The amplitude of $\mathrm{L}^{3}$ echo decreased a little and that of $\mathrm{L}_{\mathrm{w}}$ echo disappeared gradually, due to the sublimation of ice and the rough ice surface.

(5) At the 370.0-min mark: The amplitude of the $\mathrm{L}^{3}$ echo increased suddenly from the bottom line and reach a stable value, due to the fact that the electromechanical coupling factor varied and the ultrasonic energy transmitting into the ice through the steel/ice interface reduced [33]. This ultrasonic phenomenon indicated the reduction of contact surface between ice and steel plate in the drying stage. At this moment, the sublimation of the ice reached a certain level and the thermocouple detached from the ice, as shown in Figure $5 b$.

(6) At the 885.6-min mark: The amplitude of the $\mathrm{L}^{3}$ echo increased suddenly from the reducing tendency and reached a stable value at this moment, due to the fact that the electromechanical coupling factor varied and ultrasonic energy transmitting into the ice through the steel/ice interface reduced further. This ultrasonic phenomenon indicated the complete sublimation of the ice and only few minerals remained on the steel plate surface. This moment is defined as the drying end point. The drying period $\left(\Delta \mathrm{P}_{\text {DUT }}\right)$ determined by the ultrasonic $\mathrm{L}^{3}$ echo is defined as the period from the exhaust of chamber to the complete sublimation of the ice, that is, the drying end point. Compared with the typical experiment settings, the indication of drying ends for water by the amplitude variations of ultrasonic $\mathrm{L}^{3}$ echo could reduce the processing period of the $134.4 \mathrm{~min} /$ cycle and save $13 \%$ of consumed electricity. 

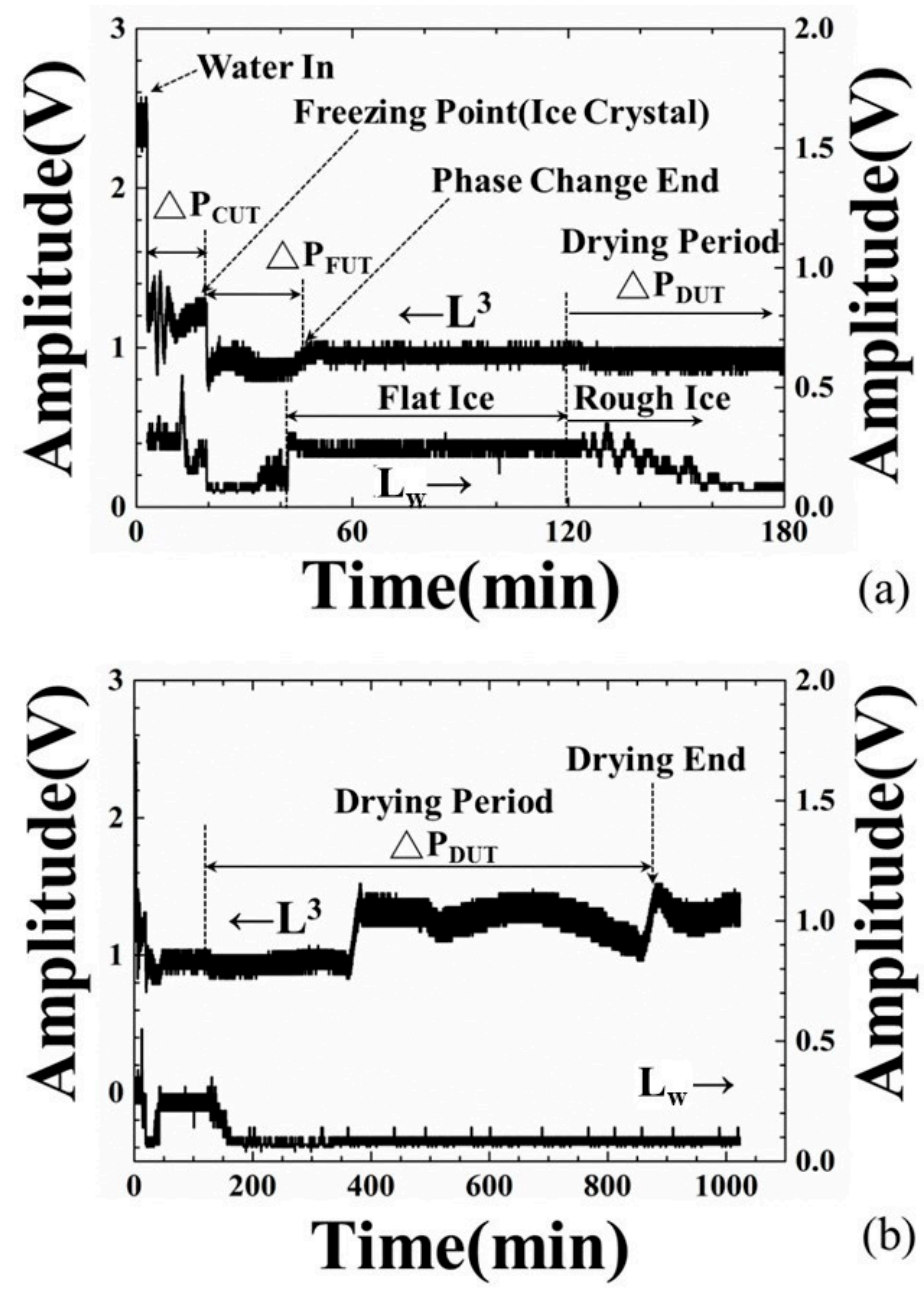

Figure 6. Amplitude variations of ultrasonic $\mathrm{L}^{3}$ and $\mathrm{L}_{\mathrm{w}}$ echoes during freeze-drying process at (a) freezing stage and (b) drying stage, indicating the water-in, freezing point (ice crystal), phase change end and drying end.

\subsection{Variation of Ultrasonic Velocity during the Freeze-Drying Process}

During the freezing process, the slow cooling speed caused bigger ice crystal nuclei than did the fast cooling time. Ultrasonic velocity has a close relationship with temperature and it is one of the indicators that shows the cooling speed of water, the phase change end and the start of sublimation. The ultrasonic velocity in the water is calculated according to the following equation:

$$
\mathrm{v}_{\mathrm{w}}=2 \mathrm{H} / \Delta \mathrm{t}
$$

where $\mathrm{H}$ is the height of the water level in Figure $3 a$ and $\Delta t$ is the time delay between the ultrasonic $\mathrm{L}^{1}$ and $\mathrm{L}_{\mathrm{w}}$ echoes in Figure $3 b$. The result is shown in Figure 7.

In Figure 7, when the water was poured into the container, the ultrasonic velocity was first measured at the 3.0 -min mark under the water temperature of $27.2{ }^{\circ} \mathrm{C}$. At that moment, the ultrasonic velocity in the water was $1588.5 \mathrm{~m} / \mathrm{s}$. From the 3.0 to the 17.4-min mark, when the water temperature decreased to $1.0^{\circ} \mathrm{C}$, the ultrasonic velocity decreased to $1434.5 \mathrm{~m} / \mathrm{s}$, indicating that the temperature of the water had decreased during the cooling process. Comparing Figure 7 with Figure 5a, the relationship between ultrasonic velocity and water temperature is expressed by the following equation.

$$
\mathrm{v}_{\mathrm{w}}\left(\mathrm{T}_{\mathrm{w}}\right)=1.42418 \times 10^{3}+1.03190 \times 10 \times T_{w}-0.15453 \times T_{w}^{2}
$$


where $\mathrm{v}_{\mathrm{w}}(\mathrm{m} / \mathrm{s})$ is the ultrasonic velocity in water and $\mathrm{T}_{\mathrm{w}}$ is the water temperature. The ultrasonic velocity decreased with the reducing water temperature. The ultrasonic velocity presented by authors in this study is higher than that presented by Bilanuik and Wang [34], due to some minerals contained in the water. Therefore, the cooling speed of water can be determined by measuring the ultrasonic velocity in the water. From the 17.4 to 38.3-min mark of the experiment, the ultrasonic velocity disappeared and the amplitude of the $\mathrm{L}_{\mathrm{w}}$ echo also decreased in noise level due to the formation of ice crystal nuclei. After the 38.3-min mark, the ultrasonic $\mathrm{L}_{\mathrm{w}}$ echo appeared again and the ultrasonic velocity gradually increased from 3586.4 to $3597.2 \mathrm{~m} / \mathrm{s}$, due to the phase change end of the water and the completion of the freezing process. From 43.0 to 120.0-min mark, the ultrasonic velocity maintained a steady level of $3597.2 \mathrm{~m} / \mathrm{s}$ for the pausing period. Therefore, ultrasonic velocity can be used to indicate the cooling speed, the phase change end and completion of the freezing process of water.

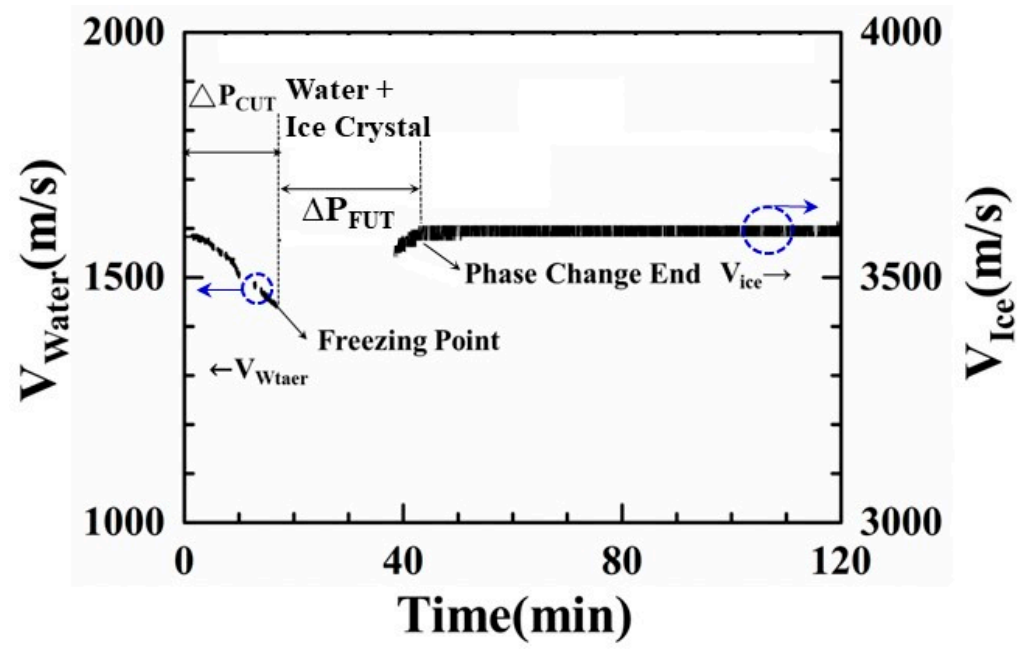

Figure 7. Ultrasonic velocity variation in the water during the freeze-drying process, which indicates the water-in, the freezing point (ice crystallization) and the phase change end.

\subsection{Visual Observation of the Container during the Freeze-Drying Process}

The dynamic physical phenomena that can be observed in the container shows the phase change from water to ice and the sublimation detail of the ice during the freeze-drying process in great detail. These phenomena could also be evidence of other measured parameters. Figure 8a-l are the photographs of the container with water/ice during the freeze-drying process at the $0-888$-min mark, respectively. The freeze-drying process observed in Figure $8 \mathrm{a}-1$ is described as follows:

(1) Figure 8a: Water was poured into the container that had a thermocouple in the middle and then the container was set on the shelf of the freeze-drying machine.

(2) Figure $8 \mathrm{~b}-\mathrm{d}$ : Most of the water was still in a liquid state. However, the water close to the bottom of the container started to become opaque and some ice crystals began to form beside the thermocouple. The ice crystals increased gradually from the bottom to the top of the container. This was an indication that the water started to freeze.

(3) Figure 8e: Half of the water became very slushy and the visibility became worse. Some air bubbles also appeared within the slush.

(4) Figure 8f: Most of the water had become frozen into ice. Some air bubbles were pushed up from the bottom to the top. The ice surface was flat, which indicated that the stress on the ice during the freezing process was reduced.

(5) Figure $8 \mathrm{~g}-\mathrm{h}$ : The chamber was exhausted and a vacuum was created. The ice sublimated from the top progressing downwards towards the bottom of the container and from the exterior inwards towards the interior of the container. The ice surface was composed of porous structure and appeared rough. 
(6) Figure 8i-j: The ice shrank more due to further sublimation. The contact surface between the ice and the steel plate was also reduced. The thermocouple seemed to detach from the ice at the 480-min mark of the process. This could explain why the sample temperature increased suddenly from -36 to $-10{ }^{\circ} \mathrm{C}$ at 390.5 -min mark. At the 540-min mark, the contact surface between the ice and the steel plate was reduced even further, which may diminish the conduction of heat being transferred from the shelf to the ice.

(7) Figure 8k-1: There was tiny amount of residual ice that remained on the surface of the steel plate at the 840-min mark. Finally, at the 888-min mark, only a little of ice crystals remained on the surface of the steel plate.

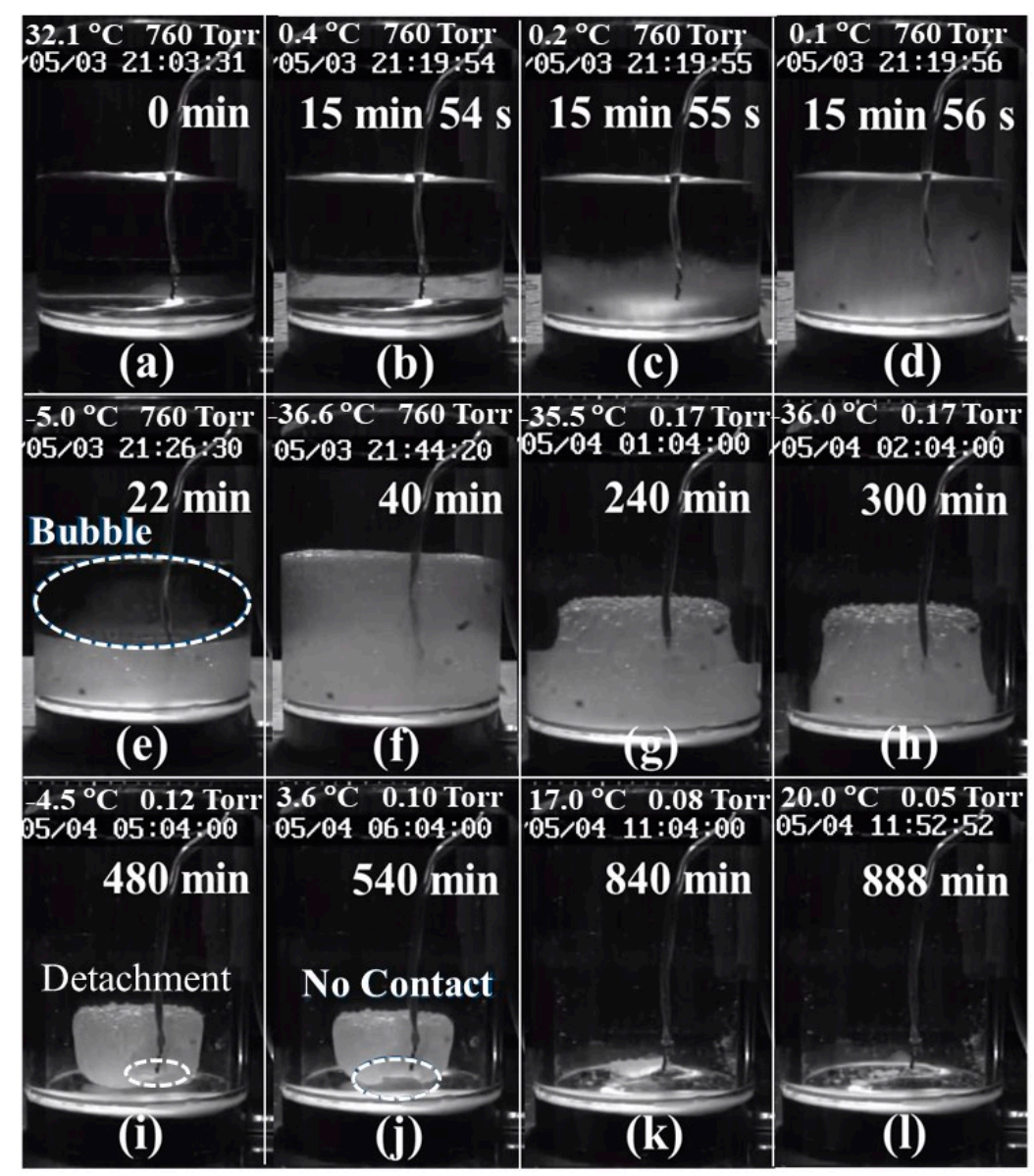

Figure 8. Photographs of the water/ice in the container during the freeze-drying process along with the corresponding process times of (a) $0 \mathrm{~min}$, (b-d) $15 \mathrm{~min} 54 \sim 56 \mathrm{~s}$, (e) $22 \mathrm{~min}$, (f) $40 \mathrm{~min},(\mathrm{~g}) 240 \mathrm{~min}$, (h) $300 \mathrm{~min},(\mathbf{i}) 480 \mathrm{~min}$, (j) $540 \mathrm{~min}$, (k) $840 \mathrm{~min}$ and (1) $888 \mathrm{~min}$.

The freeze-drying process can be observed clearly in Figure 8. These results can provide additional evidence for the previous measuring methods. However, this observing method is only suitable for the transparent container and plain solution. For the unobservable container and the opaque material, such as metal container and colored samples, the temperature and ultrasonic techniques are more capable to diagnose the mentioned phenomena. From the measured results, the thermocouple detached from the ice and further temperature information of the ice was not available. In this viewpoint, the ultrasonic technique is a more reliable and capable method for diagnosing the freeze-drying process.

\subsection{Freeze-Drying Processes of Various Water Levels}

Before applying the ultrasonic technology to the freeze-drying process, the linear relationship between ultrasonic signatures and the water level is the fundamental requirement. To verify this 
relationship, the containers, which were filled with water in the height of 5, 10,15 $\mathrm{mm}$, passed through the freeze-drying process under the shelf temperature setting of $-30^{\circ} \mathrm{C}$. In this research, the variation during the drying period will be evaluated. During the drying stage, the thermocouple cannot measure the samples' temperature profiles due to the detachment of thermocouple from the sample. The ultrasonic signals are able to diagnose the drying phenomena. The experimental results of the amplitude of the ultrasonic $L^{3}$ echo are shown in Figure 9. Figure 9a-c are the amplitude variations of ultrasonic $\mathrm{L}^{3}$ echo in water levels of $5,10,15 \mathrm{~mm}$, respectively, during the drying stage. The timings of the drying end indicated by ultrasonic $\mathrm{L}^{3}$ echo are 329.8, 526.7 and 885.6-min mark for the water levels of 5, 10 and $15 \mathrm{~mm}$, respectively. The drying periods of various water levels are also indicated. The corresponding timings of the drying end indicated by ultrasonic $\mathrm{L}^{3}$ echo are illustrated in Table 2 . It seems that there is a linear relationship between the timings of drying end and the water level.

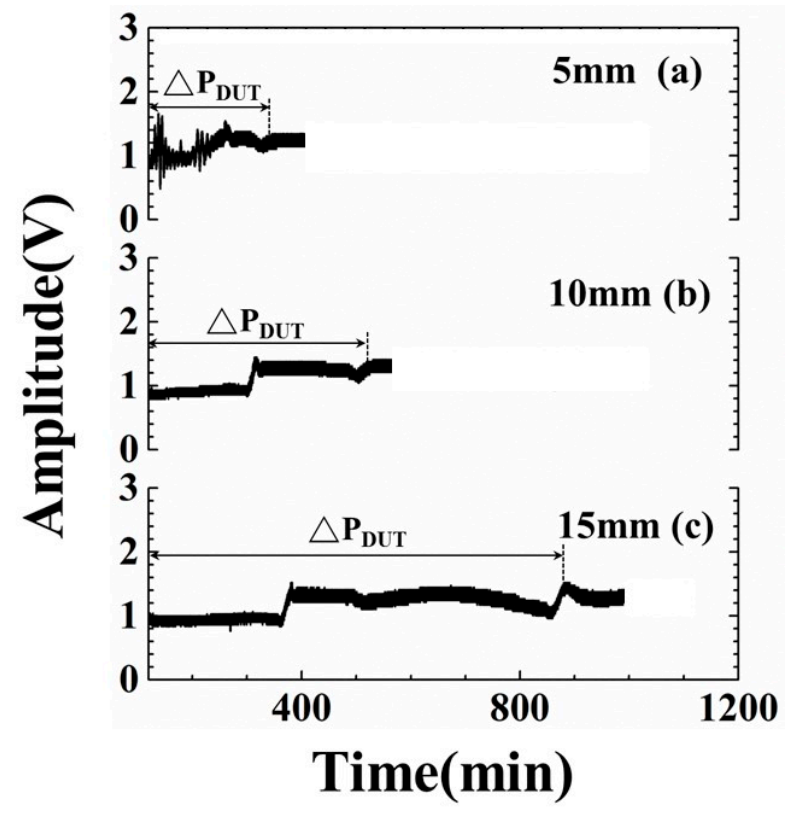

Figure 9. Amplitude variations of ultrasonic $\mathrm{L}^{3}$ echo with respect to various water levels at drying stage. Water level: (a) 5, (b) 10 and (c) $15 \mathrm{~mm}$.

Table 2. Timings and temperatures of water in, freezing point, phase change end and drying end indicated by temperature and ultrasonic $\mathrm{L}^{3}$ echo for water levels of 5, 10, $15 \mathrm{~mm}$.

\begin{tabular}{|c|c|c|c|c|c|}
\hline $\begin{array}{c}\text { Water } \\
\text { Level (mm) }\end{array}$ & Items & Watering Point & Freezing Point & $\begin{array}{c}\text { Phase } \\
\text { Change End }\end{array}$ & Drying End \\
\hline \multirow{3}{*}{5} & Time $_{\text {Temp }}(\min )$ & 3.0 & 16.3 & 24.4 & $\mathrm{~N} / \mathrm{A}$ \\
\hline & Time $_{U T}$ (min) & 3.0 & 15.8 & 20.6 & 329.8 \\
\hline & $\begin{array}{c}\text { Temperature } \\
\left({ }^{\circ} \mathrm{C}\right)\end{array}$ & 29.8 & -2.8 & -10.8 & N/A \\
\hline \multirow{3}{*}{10} & Time $_{\text {Temp }}(\min )$ & 3.0 & 14.0 & 28.9 & $\mathrm{~N} / \mathrm{A}$ \\
\hline & Time $_{U T}(\min )$ & 3.0 & 13.7 & 27.1 & 526.7 \\
\hline & $\begin{array}{c}\text { Temperature } \\
\left({ }^{\circ} \mathrm{C}\right)\end{array}$ & 30.4 & -2.4 & -14.9 & N/A \\
\hline \multirow{3}{*}{15} & Time $_{\text {Temp }}(\mathrm{min})$ & 3.0 & 19.2 & 46.7 & $\mathrm{~N} / \mathrm{A}$ \\
\hline & Time $\mathrm{UT}$ (min) & 3.0 & 19.5 & 45.8 & 885.6 \\
\hline & $\begin{array}{c}\text { Temperature } \\
\left({ }^{\circ} \mathrm{C}\right)\end{array}$ & 32.1 & -0.4 & -16.5 & N/A \\
\hline
\end{tabular}

The measured drying periods are compared with the water level for evaluating the mentioned linear relationship. The results are shown in Figure 10. The estimated error of drying period under the 
experimental conditions is less than $5 \%$. In the water level range from 5 to $15 \mathrm{~mm}$, the average drying periods indicated by ultrasonic $\mathrm{L}^{3}$ echo increase from 185.1 to $742.8 \mathrm{~min}$. The slope of the fitting line is $55.8 \mathrm{~min} / \mathrm{mm}$. The drying period is expressed as:

$$
\Delta \mathrm{P}_{\text {DUT }}=-112.8+55.8 * H
$$

where $\Delta \mathrm{P}_{\mathrm{DUT}}$ is the drying period in Figure 9 and $\mathrm{H}$ is the water level in Figure 3. Even though there are no temperature and visual information, one can still estimate the required drying period according to the filled water level based on Equation (3). In the future, this ultrasonic sensor and evaluating technology would be installed into freeze drying machine to detect the phase change and feedback the information to machine control system, as shown in Figure 1. Comparing with the typical experiment settings of $1020 \mathrm{~min}$, the ultrasonic technique can clearly indicate the dynamic phenomena and completion of cooling/freezing/drying stages at each water level before the end of the experiment for reducing the freeze-drying process and saving energy.

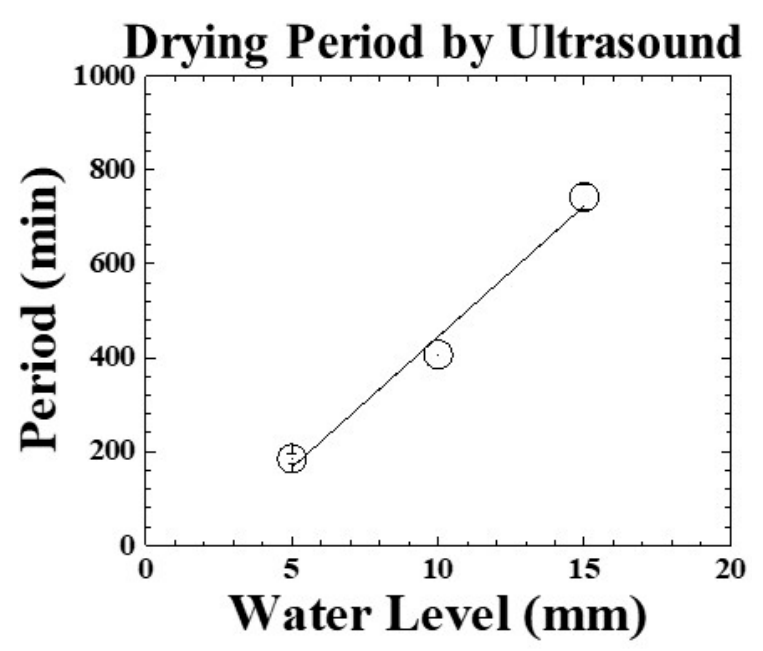

Figure 10. Drying periods measured by ultrasonic signal with respect to various water levels. Water level: 5, 10, $15 \mathrm{~mm}$.

\section{Conclusions}

In this paper, an ultrasonic transducer (UT) is integrated onto the bottom of a specially designed container to analyze the freeze-drying process of water at various water amounts. The measured ultrasonic signatures are compared with the temperature and visual records. Among these three measured methods, ultrasonic and visual records are able to document the entire progression of the freeze-drying process, including the water-in, freezing/drying points, the phase change end of the water and the cooling/freezing/drying periods. The ultrasonic velocity in the water also indicates the cooling tendency of the water. The drying period increases with the water level. The increase rate, which is evaluated by the amplitude of the ultrasonic $\mathrm{L}^{3}$ echo, is $55.8 \mathrm{~min} / \mathrm{mm}$. During the drying stage, the thermocouple cannot measure the entire temperature profile of the ice due to the detachment of the thermocouple from the ice. Only the ultrasonic signals and visual records are utilized for diagnosing the drying phenomena. However, the observing method is only suitable for the transparent container and plain solution. Comparing with the typical experiment settings, the indication of drying ends for water at level of $15 \mathrm{~mm}$ by the amplitude variations of ultrasonic $\mathrm{L}^{3}$ echo could reduce the process period of $134.4 \mathrm{~min} /$ cycle and save $13 \%$ of consumed electricity. Therefore, this study demonstrates the use of a specially designed container, integrated ultrasonic sensor and technology for analyzing and optimizing the freeze-drying process of water for saving the process cost and energy. 
Author Contributions: C.-C. Cheng initiated the idea, provided the draft and completed the revising of the paper. Y.-H. Tseng prepared the integrated sensor and practiced the experiments of freeze-drying process. S.-C. Huang analyzed the data and assisted to revise paper.

Funding: This work is funded by Ministry of Science and Technology of Taiwan, ROC under Contracts No: MOST 104-2221-E-027-121, MOST-105-2221-E-027-103 and MOST 107-3113-E-008-003.

Acknowledgments: The authors would like to provide special thanks to Hong-Ping Cheng (Department of Energy and Refrigerating Air-Conditioning Engineering, National Taipei University of Technology) for providing the useful discussions, Rei-Zhu Hsueh (Tai Yiaeh Enterprise Co., Ltd., New Taipei City, Taiwan) for providing useful maintaining assistance of freeze drying machine.

Conflicts of Interest: The authors declare no conflict of interest.

\section{References}

1. Zhao, J.H.; Liu, F.; Wen, X.; Xiao, H.W.; Ni, Y.Y. State diagram for freeze-dried mango: Freezing curve, glass transition line and maximal-freeze-concentration condition. J. Food Eng. 2015, 157, 49-56. [CrossRef]

2. Chizoba Ekezie, F.G.; Sun, D.W.; Han, Z.; Cheng, J.H. Microwave-assisted food processing technologies for enhancing product quality and process efficiency: A review of recent developments. Trends Food Sci. Technol. 2017, 67, 58-69. [CrossRef]

3. Ishwarya, S.P.; Anandharamakrishnan, C. Spray-Freeze-Drying approach for soluble coffee processing and its effect on quality characteristics. J. Food Eng. 2015, 149, 171-180. [CrossRef]

4. Monteiro, R.L.; Link, J.V.; Tribuzi, G.; Carciofi, B.A.M.; Laurindo, J.B. Microwave vacuum drying and multi-flash drying of pumpkin slices. J. Food Eng. 2018, 232, 1-10. [CrossRef]

5. Senadeera, W.; Alves-Filho, O.; Eikevik, T. Influence of drying conditions on the moisture diffusion and fluidization quality during multi-stage fluidized bed drying of bovine intestine for pet food. Food Bioprod. Process. 2013, 91, 549-557. [CrossRef]

6. Maisnam, D.; Rasane, P.; Dey, A.; Kaur, S.; Sarma, C. Recent advances in conventional drying of foods. J. Food Technol. Preserv. 2016, 1, 25-34.

7. Ahrens, D.C.; Villela, F.A.; Doni Filho, L. Physiological and industrial quality of white-oat (Avena sativa L.) seeds in intermittent drying. Rev. Bras. Sementes 2000, 22, 12-20. [CrossRef]

8. Toshniwal, U.; Karal, S. A review paper on Solar Dryer. Int. J. Eng. Res. Appl. 2013, 3, 896-902.

9. Kasper, J.C.; Friess, W. The freezing step in lyophilization: Physico-chemical fundamentals, freezing methods and consequences on process performance and quality attributes of biopharmaceuticals. Eur. J. Pharm. Biopharm. 2011, 78, 248-263. [CrossRef]

10. Siew, A. Freeze-drying process optimization. Pharm. Technol. 2018, 42, 18-23.

11. Ratti, C. Hot air and freeze-drying of high-value foods: A review. J. Food Eng. 2001, 49, 311-319. [CrossRef]

12. Rahman, M.S.; Guizani, N.; Al-Khaseibi, M.; Al-Hinai, S.A.; Al-Maskri, S.S.; Al-Hamhami, K. Analysis of cooling curve to determine the end point of freezing. Food Hydrocoll. 2002, 16, 653-659. [CrossRef]

13. Mellor, J.D.; Bell, G.A. Freeze-Drying-The Basic Process. In Encyclopedia of Food Sciences and Nutrition; Elsevier: Amsterdam, The Netherlands, 2003; pp. 2697-2701. ISBN 9780122270550.

14. Wang, D.Q.; Hey, J.M.; Nail, S.L. Effect of Collapse on the Stability of Freeze-Dried Recombinant Factor VIII and $\alpha$-Amylase. J. Pharm. Sci. 2004, 93, 1253-1263. [CrossRef]

15. Tang, X.; Nail, S.L.; Pikal, M.J. Freeze-drying process design by manometric temperature measurement: Design of a smart freeze-dryer. Pharm. Res. 2005, 22, 685-700. [CrossRef]

16. Chang, B.S.; Patro, S.Y. Freeze-drying Process Development for Protein Pharmaceuticals. In Lyophilization of Biopharmaceuticals; American Association of Pharmaceutical Scientists: Arlington, VA, USA, 2004; pp. 113-138. ISBN 978-0-9711767-6-8.

17. Pikal, M.J.; Shah, S.; Roy, M.L.; Putman, R. The secondary drying stage of freeze drying: Drying kinetics as a function of temperature and chamber pressure. Int. J. Pharm. 1990, 60, 203-207. [CrossRef]

18. Breen, E.D.; Curley, J.G.; Overcashier, D.E.; Hsu, C.C.; Shire, S.J. Effect of moisture on the stability of a lyophilized humanized monoclonal antibody formulation. Pharm. Res. 2001, 18, 1345-1353. [CrossRef]

19. Rahman, M.S. Handbook of Food Preservation, 2nd ed.; Rahman, M.S., Ed.; Taylor \& Francis Group: Milton Park, UK, 2007; ISBN 9781845697587. 
20. Nail, S.; Tchessalov, S.; Shalaev, E.; Ganguly, A.; Renzi, E.; Dimarco, F.; Wegiel, L.; Ferris, S.; Kessler, W.; Pikal, M.; et al. Recommended Best Practices for Process Monitoring Instrumentation in Pharmaceutical Freeze Drying-2017. AAPS PharmSciTech 2017, 18, 2379-2393. [CrossRef]

21. Malik, N.; Gouseti, O.; Bakalis, S. Effect of freezing with temperature fluctuations on microstructure and dissolution behavior of freeze-dried high solid systems. Energy Procedia 2017, 123, 2-9. [CrossRef]

22. Tseng, Y.H.; Cheng, C.C.; Cheng, H.P.; Lee, D. Novel Real-Time Diagnosis of the Freezing Process Using an Ultrasonic Transducer. Sensors 2015, 15, 10332-10349. [CrossRef]

23. Hellier, C.J. Handbook of Nondestructive Evaluation; McGraw-Hill Companies, Inc.: New York, NY, USA, 2003; ISBN 007139947X.

24. Cheng, C.C.; Yang, S.Y.; Lee, D. Novel real-time temperature diagnosis of conventional hot-embossing process using an ultrasonic transducer. Sens. Switz. 2014, 14, 19493-19506. [CrossRef] [PubMed]

25. Wu, Y.L.; Cheng, C.C.; Kobayashi, M.; Yang, C.H. Novel design of extension nozzle and its application on real-time injection molding process diagnosed by ultrasound. Sens. Actuators A Phys. 2017, 263, 430-438. [CrossRef]

26. Cheng, C.-C.; Wu, C.-L.; Wu, K.-T.; Yang, S.-Y. Real-time diagnosis of gas-assisted hot embossing process by ultrasound. Polym. Eng. Sci. 2013, 53, 2175-2182. [CrossRef]

27. Kažys, R.; Voleišis, A.; Voleišienė, B. High temperature ultrasonic transducers: Review. Ultrasound 2008, 63, 7-17.

28. Takahashi, M.; Ihara, I. Ultrasonic monitoring of internal temperature distribution in a heated material. Jpn. J. Appl. Phys. 2008, 47, 3894-3898. [CrossRef]

29. Cheng, C.C. Micromolding of polymer nanocomposites diagnosed by ultrasound. J. Polym. Eng. 2010, 30, 95-108. [CrossRef]

30. Passot, S.; Tréléa, I.C.; Marin, M.; Galan, M.; Morris, G.J.; Fonseca, F. Effect of controlled ice nucleation on primary drying stage and protein recovery in vials cooled in a modified freeze-dryer. J. Biomech. Eng. 2009, 131, 074511. [CrossRef] [PubMed]

31. Cheng, C.-C.; Young, S.-L.; Chen, H.-Z.; Yang, S.-Y. Substrate Effect on Characteristics of PbZrxTi1-xO3 (PZT) Film. Integr. Ferroelectr. 2014, 150, 51-58. [CrossRef]

32. Shuyu, L. Load characteristics of high power sandwich piezoelectric ultrasonic transducers. Ultrasonics 2005, 43, 365-373. [CrossRef]

33. Arnold, F.J.; Roger, L.L.B.; Gonçalves, M.S.; Mühlen, S.S. Electrical Impedance of Piezoelectric Ceramics under Acoustic Loads. Ecti Trans. Electr. Eng. Electron. Commun. 2014, 12, 48-54.

34. Bilaniuk, N.; Wong, G.S.K. Speed of sound in pure water as a function of temperature. J. Acoust. Soc. Am. 1993, 93, 1609-1612. [CrossRef]

(C) 2019 by the authors. Licensee MDPI, Basel, Switzerland. This article is an open access article distributed under the terms and conditions of the Creative Commons Attribution (CC BY) license (http://creativecommons.org/licenses/by/4.0/). 